\section{Supposed Risso's Grampus in the Mersey}

THE importance that authorities in tidal districts be acquainted with the fact that, under an arrangement made some few years ago, all large cetaceans stranded on the shores of Great Britain should be offered to the British Museum before any decision is made to dispose of them, is well borne out by the unfortunate destruction of a rare cetacean recently stranded in the Mersey. The flood tide of December 10, stranded a large cetacean in the Mersey at Widnes, and various unofficial reports circulated suggested it to be a porpoise, dolphin, or killer whale. Immediately upon discovering that no local museum or university had been informed of the rarity, the Merseyside Naturalists' Association went to considerable trouble to collect all available evidence and photographs and to interview all people who had handled the specimen. Through some misunderstanding, it appears that although the customs authorities had told the transporter company who recovered the whale that any scientifically interested body could have it, the Upper Mersey Conservators took possession of the carcass the day following its stranding, cut it up into pieces and returned it to the river from one of their vessels.

Evidence which was gathered by the Merseyside Naturalists' Association strongly suggests that the animal was a Risso's grampus (Grampus griseus), of which there is no previous Lancashire or Cheshire record. The report of evidence it collected gives: Length, $11 \mathrm{ft.} 2$ in.; upper parts : dark grey, almost black, blotched and streaked plainly with greyish-white, dorsal fin broad and high; head : no teeth in upper jaw; lower jaw with a few rather blunt teeth spaced about $0 \cdot 75$ in. apart; lower jaw a shade shorter than upper jaw ; whitish tinge to muzzle and greyish tinge to head; head large and swollen like that of pilot whale; underparts white, smooth; flippers long, narrow and pointed; tail flukes narrow. No scientific measurements had been taken owing to the surprising and unannounced destruction of the carcass, but a photograph taken by a local man had been secured. The specimen was still alive and blowing when stranded and roped.

\section{The Meteorological Office}

THE recently issued report of the Director of the Meteorological Office for the year ending March 31, 1939 (H.M. Stationery Office. 9d. net), is largely occupied with a description of changes of organization arising from the rapid expansion of the Office, due mainly to the expansion of the Royal Air Force; it contains also an account of the methods adopted for dealing with routine requirements of the different services and of civil aviation. For these reasons a more careful perusal of the report is necessary than has generally been the case in the past in order to find items of purely scientific interest, although, it is curious to note, the decision was made during the period under review to make organized research a part of the normal work of the Office, instead of leaving research to individual entorprise on the part of the scientific staff.
The most important instrumental problem that has been pursued has been the development of the radio-sonde method of measuring the pressure, temperature and humidity of the atmosphere up to heights of 10 miles or more. The apparatus arrived at has been developed in collaboration with the National Physical Laboratory. It is carried by a free balloon, and transmits radio signals which are modulated in a manner dependent on the physical state of the atmosphere with which the balloon is surrounded at the moment. Fifty ascents were made, in most of which a Dines meteorograph was attached so that a check on the indications of the radio transmitter was available eventually on those occasions when the instruments were recovered. Much time was spent in trying to eliminate various sources of error that were encountered. Trials of a radio method of measurement of winds at great heights were continued, the method consisting of observations by two distant radio direction finding stations of the position of a small radio transmitter carried by a balloon. The main difficulty arose from the deflection of the radio signals by surface objects, which necessitated elaborate calibration. During the year under review the use of the cloud searchlight for rapid determination of cloud height at night was greatly extended. Improved specifications for pilot balloons were considered, with the view of avoiding the rapid deterioration experienced in hot climates, also improved methods of storage.

\section{Terminal Velocities}

Dr. Herbert Chatley prepared a paper on 'terminal velocities' for delivery to the Junior Institution of Engineers on October 13. It is now published in the December issue of the Journal of the Institution. In many engineering and physical problems of the present day, the question often arises as to the maximum velocity developed when a body falls in a fluid medium. To give a rough idea of the terminal velocities, Dr. Chatley compares the impact velocity of a stream-lined aerial bomb and the speed with which the finest clay suspensions settle in water. Between these speeds he considers the landing speed of parachutes, the fall of rain or oil-drops, the vertical current speeds necessary in coal dust or grain eleva. tors, the suspension of sand or silt in rivers, and the settlement of dust particles in a room.

When an elevated body is released, it falls earthwards according to the law of gravitation. As it proceeds, the resistance of the air or water increases up to a definite value, namely, when this resistance equals the weight of the body. When this happens, the velocity remains constant and is called the term. inal velocity. A sand particle one micron in diameter has a terminal velocity in water of about $0.001 \mathrm{~mm}$. per second; in air it is about ninety times as great. One of the most useful applications of the terminal velocity is in,the computation of the power required to sustain bodies when placed in a current of fluid. For example, in the elevation of grain from a hopper or ship's hold to a level somewhat above the receiver, out of which it flows to a second container (say, 50 feet 